Portland State University

PDXScholar

2018

\title{
Biting the Hand that Heals: Mistreatment by Patients and the Well-being of Healthcare Workers
}

\author{
Aysegul Karaeminogullari \\ Portland State University \\ Berrin Erdogan \\ Portland State University \\ Talya N. Bauer \\ Portland State University, talyabauer@pdx.edu
}

Follow this and additional works at: https://pdxscholar.library.pdx.edu/busadmin_fac

Part of the Human Resources Management Commons, and the Other Medicine and Health Sciences Commons

Let us know how access to this document benefits you.

\section{Citation Details}

Karaeminogullari, Aysegul; Erdogan, Berrin; and Bauer, Talya N., "Biting the Hand that Heals: Mistreatment by Patients and the Well-being of Healthcare Workers" (2018). Business Faculty Publications and Presentations. 94.

https://pdxscholar.library.pdx.edu/busadmin_fac/94

This Post-Print is brought to you for free and open access. It has been accepted for inclusion in Business Faculty Publications and Presentations by an authorized administrator of PDXScholar. Please contact us if we can make this document more accessible: pdxscholar@pdx.edu. 


\title{
Biting the hand that heals: \\ Mistreatment by patients and the well-being of healthcare workers
}

\begin{abstract}
Purpose - This study aimed to explore the relationship between stress due to mistreatment by patients and caregivers’ own well-being indicators (anxiety, depression, and behavioral stress indicators). Based on predictions consistent with the job demands-resources model (JD-R), it was anticipated that satisfaction with job resources would moderate the relationship between mistreatment by patients and well-being indicators.

Design/methodology/approach - Hypotheses were tested with a sample of 182 employees in a leading training and research university hospital in Istanbul, Turkey. Results were partially replicated for a separate sample of 122 healthcare workers. Data were collected using survey methodology.
\end{abstract}

Findings - Our findings suggest that patient injustice is positively related to depression and behavioral stress indicators when satisfaction with job resources is high. Results illustrate that satisfaction with job resources have a sensitizing, rather than a buffering, role on the relation between mistreatment by patients, depression, and behavioral stress indicators, negatively affecting employees with higher levels of satisfaction with job resources.

Originality/value - Organizational justice researchers recently started recognizing that in addition to organizational insiders, organizational outsiders such as customers and patients may also be sources of fair and unfair treatment. Based on this stream of research, unfair treatment from outsiders is associated with retaliation and a variety of negative employee outcomes. Our study extends the currently accumulated work by examining how mistreatment from care recipients relates to healthcare workers’ own health outcomes.

Keywords Healthcare, Mistreatment by patients, Well-being, Job-demands resources model 
Paper type Research paper

\section{Biting the hand that heals:}

\section{Mistreatment by patients and well-being of healthcare workers}

\section{Introduction}

Employee perceptions of interactional fairness have received considerable attention in the academic literature (e.g., Colquitt et al., 2001). Generally, researchers have established that employees perceive fair interactions when they are treated with dignity and respect (Bies and Moag, 1986) whereas they perceive unfairness and mistreatment in cases of undeserved prejudicial statements (Rupp and Spencer, 2006) or hurtful personal attacks (Bies and Moag, 1986). Until recently, intra-organizational sources of unfairness, including the organization, supervisors, and coworkers, have been within the scope of investigations (e.g., Cropanzano et al., 2002; Folger and Konovsky, 1989). However, scholars have begun to examine a relatively new source of interactional mistreatment - external parties such as customers, guests, or patients of an organization (Ho and Gupta, 2014; Rupp and Spencer, 2006).

A perplexing reality is that even employees who dedicate their careers to helping the health and well-being of others such as nurses (Speroni et al., 2014), emergency department workers (Gates et al., 2006), and firefighters (Sliter and Boyd, 2015) are often targets of unfair, rude, disrespectful, and sometimes violent treatment. In an extreme example, relatives of a patient who died during treatment attacked a doctor in India, resulting in an indefinite strike by medical personnel (Deccan Herald, 2016). The problem is not limited to a few isolated cases. In a countywide report of Los Angeles, general and mental healthcare workers, in comparison with other employee groups, have reported higher rates of workplace assaults (Sullivan and Yuan, 


\section{BITING THE HAND THAT HEALS}

1995). A cross-sectional study of employees in a Midwest healthcare organization showed that nearly $31 \%$ of employees reported experiencing non-physical aggression (Findorff et al., 2004). Given this prevalence, stress caused by mistreatment from customers and care recipients has the potential to result in undesirable employee outcomes, making it a critically important topic of study. To date, scholars have typically focused on how employees retaliate against customers or how job attitudes fluctuate when they experience customer mistreatment (e.g., Shao and Skarlicki, 2014; Skarlicki et al., 2008). What is rare in this stream of research are studies exploring how mistreatment by the people one is serving affects one's own health and wellbeing. Referring to this research gap, our aim in this study is to explore two key questions: What is the relationship between stress due to patient mistreatment and employees' physical and mental well-being? And what are the factors that could ameliorate the negative effects of mistreatment by patients? Hence, we conducted two independent studies to test the effects of mistreatment by patients on three indicators (anxiety, depression, and behavioral stress indicators) of employee wellbeing. In Study 1 we operationalized mistreatment by patients as perceived stress due to patients, and in Study 2 as interpersonal injustice attributable to patients.

In these two studies together, we test a model linking unfair treatment from patients and caregiver well-being (e.g., anxiety, depression, and behavioral stress indicators) while investigating the moderating role of job resources. The first contribution of this study is to expand the existing literature on customer mistreatment by examining caregiver well-being as an outcome of stress due to patient mistreatment. De Lange et al. (2005) document that stressful work diminishes psychological and physical well-being. Estimations of a Gallup poll suggest that the cost of lost productivity due to unhealthy workers is $\$ 153$ billion a year (Ciccone, 2011). 


\section{BITING THE HAND THAT HEALS}

Thus, employee health is a critically important outcome for employees and their organizations, as well as the society at large.

Second, while scholars have investigated the direct effects of customer injustice and mistreatment on negative emotional states, less is known about potential boundary conditions of these relationships. Caregiving occupations have a high risk of mistreatment (LeBlanc and Kelloway, 2002), but jobs in this sector may also provide resources that potentially strengthen and empower the employee. Based on the job demands-resources (JD-R) model (Bakker and Demerouti, 2007; Demerouti et al., 2001), aspects of the work environment that are functional in helping achieve work goals, stimulate learning, or otherwise reduce demands of one's job interact with job demands to predict stress and outcomes. Consistent with this model, we examine how satisfaction with specific job resources may affect the relationship between stress arising from patient injustice, mental health, and unhealthy behaviors.

Finally, our third contribution is our examination of the proposed model in two samples of Turkish healthcare workers who provide service in a setting with high levels of interpersonal tension (Maslach and Jackson, 1984; Vredenburgh et al., 1999). While customer orientation in service-providing occupations creates a power inequality between customers and service providers (Grandey et al., 2004), patients' vulnerability and dependency on the caregiver are mitigating factors in the case of healthcare setting, making healthcare workers a unique population to study. Due to the growing body of verbal and physical abuse reports in daily press and descriptive research that puts forth the extensiveness of the problem (Kisa, 2008), more empirical studies are needed in this unique context.

In summary, this current study attempts to provide three contributions to the literature. First, we aim to extend the existing knowledge on the outcomes of stress caused by outsider 


\section{BITING THE HAND THAT HEALS}

injustice by focusing on mental health problems and risky health behaviors as potential outcomes. Second, we attempt to make a contribution by examining whether job related resources could play a buffering role. Finally, the study addresses mental and behavioral health outcomes of healthcare workers under a fresh light within the Turkish healthcare context. This strengthens the impact of the current research in that it provides insight into the theoretical literature on outsider mistreatment and also contributes to scholarly literature on a topic that is important to society.

\section{Theory and Hypotheses}

\section{Outsider Mistreatment and Health Outcomes}

Perceptions of injustice and mistreatment from organizational insiders are related to symptoms of stress (e.g., Cropanzano et al., 2005). Even though these results provide support for the potential relationship of injustice perceptions and employee health, little is known about how injustice from outsiders affects employees. Being a relatively new focus of interest in the management and organizational behavior literatures, customer mistreatment tendencies have been explored under different labels such as unfairness (Berry and Seiders, 2008), deviance (Moschis and Cox, 1989), and uncooperative behaviors (Bitner et al., 1994). Based on these related literatures, how customers and other outsiders treat employees has implications for workplace behavior.

Introducing customers as a possible source of mistreatment, Rupp and Spencer (2006) showed that perceptions of unfair treatment from customers related to higher levels of emotional labor and difficulty to comply with display rules. Customer mistreatment researchers predominantly focused on how employees retaliate against customers who treat them unfairly (e.g., Yang and Diefendorff, 2009) and how employees feel about their jobs in reaction to unfair treatment from customers (Ho and Gupta, 2014). In the two studies examining how customer 


\section{BITING THE HAND THAT HEALS}

injustice may relate to the health of customer facing employees, Dormann and Zapf (2004) showed that customer related social stressors predicted burnout. Grandey et al. (2004) provided additional support for the negative effects of customer mistreatment with their research results revealing the positive relationship of both the frequency and stress appraisal of customer aggression with emotional exhaustion. In the healthcare literature, researchers examined the implications of patient mistreatment on caregiver burnout (Campana and Hammoud, 2015).

Based on this body of research, it is plausible that patient mistreatment will have implications for the mental and physical health of caregivers. Among the mental outcomes of interest, healthcare workers who are targets of mistreatment from patients are more likely to feel depressed and anxious. Depression and anxiety are two distinct indicators of mental health (Sowislo and Orth, 2013), with the former indicating a general disinterest in life and work, whereas the latter refers to feelings of panic and heightened levels of fear and nervousness. Healthcare professionals who are mistreated by the very people they are trying to help and take care of are likely to be at higher risk of these mood disorders.

Further, because mistreatment by patients is likely to be a chronic stressor that could occur on a regular basis, it may also result in maladaptive coping mechanisms. Workplace stress is related to excessive alcohol consumption (Liu et al., 2014), smoking (Caplan, 1971), and eating disorders (Torres and Nowson, 2007) suggesting that unhealthy behavioral consequences may be regarded as potential expressions of stress responses to patient injustice. The overlapping, conjunctive, and deleterious effects of these coping mechanisms have clearly been documented in extensive medical research (Bucik and Brenk, 1997; Granner et al., 2002; Saules et al., 2004) and considered under the health symptoms umbrella term (Kasl et al., 1975; Pritchard et al., 2007). In light of past literature, our focus is on cigarette, alcohol, analgesic and 


\section{BITING THE HAND THAT HEALS}

psychopharmaceutical consumption and irregular eating (Bucik and Brenk, 1997) as initial maladaptive mechanisms for coping with stress (Parks and Anderson, 2004).

\section{Moderating Role of Job Related Resources}

To date, research examining organizational factors that buffer the effects of outsider injustice is limited. One theory that may provide insight into this gap is the job demands-resources (JD-R) model, which focuses on the interaction effects of certain job characteristics (Bakker et al., 2003). This model differentiates two aspects of work environment and proposes a dual process where these two aspects interact to determine the emergence and development process of occupational stress levels.

The first of these two dimensions is job demands, which represents the physical, emotional, perceptual, or cognitive costs of a certain occupation. Role ambiguity, job insecurity, negative coworker or supervisor relationships, extreme work load, work underload, abrasive interactions with customers, poor environmental conditions are some examples of job demands. The second dimension in the job-demands resources model refers to the job resources, which are proposed to provide a balance against the job demands. Resources may be a variety of physical, psychological, social, or organizational aspects of the job that are supportive in nature. Job resources are the facets of a job which help the employee in goal accomplishment, alleviate psychological or physiological costs, or improve the situation (Bakker et al., 2004). Examples include assistive and encouraging relationships with coworkers or supervisors, task clarity, career opportunities, autonomy, and constructive feedback.

The JD-R model (Demerouti et al., 2001) states that every occupation has its unique demands and resources. Rather than suggesting particular demands and resources, this view provides a flexible approach, taking the varied circumstances of different occupational settings. 


\section{BITING THE HAND THAT HEALS}

The model proposes that job demands and job resources are two distinct processes concurrently affecting employees, the former fostering exhaustion and health problems and the latter supporting well-being, engagement and performance. With its comprehensive conceptualization, JD-R model provides a convenient framework for testing the buffer effects (Xanthopoulou et al., 2007).

The availability of resources determines the degree to which workplace stressors (such as unfair treatment) affects employees (Bakker and Demerouti, 2007; Demerouti et al., 2001). Applying the JD-R model, stress due to mistreatment by patients represents a high job demand condition, exhausting mental and physical resources of healthcare professionals and so diminishing their mental and physical health. Based on the model, given the theory and empirical evidence summarized, we propose that satisfaction with the job resources available to the individual should buffer the harmful effects of patient injustice on stress related mental and physical health outcomes. In short, our model summarized in Figure 1 predicts that mistreatment by patients will interact with satisfaction with the available job resources to predict mental and physical health. Our rationale culminates in the following hypotheses:

Hypothesis 1. Satisfaction with job resources moderates the relationship between mistreatment by patients and mental health outcomes such that the relationship between mistreatment, anxiety (Hypothesis 1a) and depression (Hypothesis 1b) is less positive when satisfaction with job resources are higher.

Hypothesis 2. Satisfaction with job resources moderates the relationship between mistreatment by patients and behavioral stress indicators such that the relationship is less positive when job resources are higher.

\section{Study 1 Method}




\section{BITING THE HAND THAT HEALS}

\section{Sample and Procedures}

We collected data from patient-interfacing employees of a leading training and research university hospital in Istanbul, Turkey. We distributed the questionnaires to all 290 healthcare workers whose names appeared on the hospital website. We distributed the paper-and-pencil surveys along with an empty envelope to allow participants return questionnaires confidentially. The research was executed on-site. The first author paid daily visits to each unit for a period of two weeks so that participants could directly give completed surveys to the researcher. A total of 182 healthcare employees participated and returned the questionnaire for an overall response rate of $63 \%$. Of the 182 employees, 53\% were female and $89 \%$ were employed full-time. The mean age of the healthcare employees was 31 years $(S D=8)$. The sample included several job types such as physicians, surgeons, assistants, nurses, midwives, patient advisors, practitioners, and medical interns working in one of the 36 departments of the university hospital. Participation in the study was voluntary. Responses were anonymous.

\section{Measures}

We administered the survey in Turkish following a back-translation procedure (Brislin et al., 1973). Unless otherwise noted, employees responded to a 5-point Likert-type scale (1 = strongly disagree and 5 = strongly agree).

Mistreatment by patients. We measured mistreatment by patients using six items developed by Cooper, Rout, and Faragher (1989) which assesses perceived stress due to patients. This scale was based on in-depth interviews with 42 general practitioners. Response options ranged from "no stress at all” to "a source of extreme stress". A sample item was "fear of assault during night visits” $(\alpha=.75)$. 


\section{BITING THE HAND THAT HEALS}

Satisfaction with job resources. We used the 10-item job facet satisfaction scale by Warr, Cook, and Wall (1979) in order to measure employees’ access to job related resources by providing a list of job resources and asked the participants to indicate how satisfied they were for each item. A sample item was "freedom to choose your own method of working" $(\alpha=.87)$.

Anxiety. In order to measure anxiety we used the eight item Crown-Crisp Experiential Index (Crown and Crisp, 1966). We asked the respondents to report the extent to which they experienced each symptom recently. A sample item was “feeling upset for no reason” ( $\alpha=.83)$.

Depression. For the measurement of depression we used a second subscale of the CrownCrisp Experiential Index (Crown and Crisp, 1966). The subscale included eight items. We asked the respondents to report the degree to which they experienced each symptom recently. A sample item was "feeling life is too much effort" $(\alpha=.77)$.

Behavioral stress indicators. We assessed behavioral indicators of stress via a question list we developed based on Bucik and Brenk (1997) to measure risky health habits, specifically “cigarette consumption,” “alcohol consumption,” “analgesics consumption,” “psychopharmaceutical consumption,” and “irregular eating.” We provided a list of risky health habits and asked the participants whether or not they engaged in these listed indicators. We gave participants 1 point for each indicator, creating an index of behavioral stress indicators. Thus, responses ranged between 0 and 5 .

Control variables. Following past research (Bolger and Zuckerman, 1995; Caplan et al., 1975; Kirmeyer, 1988; Spector and O’Connell, 1994), we controlled for Type A personality and sex. Even though Type A personality was not a primary interest in our research, we measured and included it as a control variable due to the existing literature in which individuals with Type A personality are characterized to show a much greater than normal response to uncontrollable 


\section{BITING THE HAND THAT HEALS}

stressors (Carver, 1980). The findings of empirical studies indeed support this potential

(Kirmeyer, 1988; Newton and Keenan, 1990; Spector and O’Connell, 1994). We measured Type A personality using the Turkish adaptation of Rathus and Nevid (1989)’s Type A Personality Scale by Batıgün and Şahin (2006). A sample item was "feeling an urge to do your duties immediately and quickly” $(\alpha=$.83). Sex $(1=$ female, $0=$ male $)$ was also controlled for in all analyses.

\section{Results and Discussion}

Means, standard deviations, and correlations among variables are presented in Table 1 . We tested our hypotheses using hierarchical regression procedures in SPSS 23. A hierarchical regression model was conducted separately for each outcome variable (anxiety, depression, and behavioral stress indicators), controlling for Type A and sex. For each dependent variable, we entered variables into the model in three separate steps. In Step 1, we entered the control variables. In Step 2, we entered the centered main effects and in Step 3, we entered the interaction term (created using centered predictor and moderator). We examined the significance of coefficients and change in $R^{2}$. Using the methods described by Aiken, West and Reno (1991), observed interactions were further probed and we conducted simple slope analyses.

Insert Table 1 about here

The results presented in Tables 2 and 3 provided preliminary support for Hypothesis $1 \mathrm{~b}$ and 2 but no support for Hypothesis 1a. Specifically, the interaction term of mistreatment by patients with satisfaction with job resources was significant for both depression $(\beta=.16, p<.05$, $\left.\Delta \mathrm{R}^{2}=.02\right)$ and behavioral stress indicators $\left(\beta=.22, p<.01, \Delta \mathrm{R}^{2}=.05\right)$, providing preliminary 


\section{BITING THE HAND THAT HEALS}

support for these two hypotheses. However, unlike our predictions, results supported a different pattern of relationships. While we posited that job resources would buffer the relationship between mistreatment by patients and dependent variables, results revealed that the interactions were significant but in a different direction from our expectations.

Insert Table 2 and Table 3 about here

The plot of the significant interaction between mistreatment by patients and satisfaction with job resources presented in Figure 2 and simple slope analysis revealed a significant positive relation between mistreatment by patients and depression only for employees with a high level of satisfaction with job resources $(\beta=.22, t=2.33, p<.05)$, whereas there was no significant relation for employees with lower levels of satisfaction with job resources $(\beta=-.07, t=-.67, p>$ .05). Instead, employees who expressed dissatisfaction with resources had uniformly high levels of reported depression regardless of the level of mistreatment by patients. Mistreatment by patients was positively related to depression only for employees who reported high levels of satisfaction with resources.

The plot of the interaction for behavioral stress indicators presented in Figure 3 and simple slope analyses indicated that satisfaction with job resources moderated the effect of mistreatment by patients on behavioral stress indicators, such that mistreatment by patients was positively related to unhealthy habits at high levels of satisfaction with job resources ( $\beta=.26, t=$ 2.78, $p<.01$ ), but was unrelated to unhealthy habits at low levels of satisfaction with job resources $(\beta=-.12, t=-1.20, p>.05)$. 


\section{BITING THE HAND THAT HEALS}

Our measure of behavioral stress indicators was a count variable representing the number of unhealthy health habits the individuals displayed. For exploratory purposes, we also conducted a binomial hierarchical logistic regression to examine which of the individual behavioral stress indicators were predicted by our interaction term. Our results showed that the interaction term was close to significance for smoking $(\mathrm{B}=.41, \mathrm{SE}=.21$, Wald $=3.80, p=.051)$ and significant for analgesic consumption $(\mathrm{B}=.46, \mathrm{SE}=.21$, Wald $=4.93, p<.05)$ and irregular eating $(\mathrm{B}=.45, \mathrm{SE}=.22$, Wald $=3.96, p<.05)$.

\section{Discussion}

As expected, we found that level of satisfaction with resources moderated the effects of mistreatment by patients on both depression and behavioral stress indicators (Hypothesis $1 \mathrm{~b}$ and 2). Not expected, however, was the direction of this effect. Given the results of Study 1, the direction of the significant relations was not consistent with our proposed initial expectations, and in fact higher satisfaction with job resources sensitized the healthcare employees towards mistreatment by patients. This finding is inconsistent with our JD-R theory based expectations. Mistreatment by patients is a real concern and threat for healthcare employees, and this raises the necessity of going beyond prevention policies and executing appropriate support mechanisms. The unexpected findings of this study calls for further exploration of the complex interaction between satisfaction with job resources and mistreatment by patients.

Mistreatment by patients may be attributed to a variety of causes by healthcare employees. For example, they might be empathizing with the patients and blame their organizations for not providing better service to customers while they are capable of providing satisfactory job resources to employees. Thus, mistreatment by patients might not be an adequate 


\section{BITING THE HAND THAT HEALS}

variable to capture the unfairness in the exchange relationship between patients and healthcare employees.

In Study 1 we operationalized mistreatment by patients due to patient injustice using selected items from a measurement tool originally developed to measure job stressors. However, researchers examining customer mistreatment of employees utilized a variety of approaches, including customer related stressors (Dormann and Zapf, 2004), customer aggression (Grandey et al., 2004), and customer incivility (Arnold and Walsch, 2015) among others.

Drawing heavily from justice theory, customer mistreatment researchers argue that social norm breaches cause negative emotions (Lavelle et al., 2007; Rupp and Cropanzano, 2002; Rupp and Spencer, 2006). Thus, the investigation of the same research questions on a justice framework, replicating Study 1 findings using a scale more directly measuring justice would be appropriate and might contribute to a broader literature.

\section{Study 2 Method}

The purpose of Study 2 was to examine the generalizability of Study 1 findings and to test the hypothesis that satisfaction with job resources is a boundary condition of the relationship between unfair treatment from patients and three indicators of employee well-being. Sample and Procedures

We designed an online survey and sent the anonymous link to recruit participants using a snowball sampling methodology. We utilized social media and personal contacts and asked them to forward the surveys to healthcare workers in Turkey. This approach resulted in a sample of 122 patient-interfacing employees from many different organizational settings such as hospitals (61.3\%), clinics (6.6\%), private practices (8.6\%), emergency rooms (.6\%), occupational medicine units (3.6\%), dialysis centers (1.8\%), university hospitals (2.4\%), public health centers 


\section{BITING THE HAND THAT HEALS}

(3.6\%), and others (11.5\%). Organizations varied with regards to size. Of the respondents, $34 \%$ reported working in organizations with 50 or fewer employees, $17 \%$ with $51-100,27 \%$ with 101 $500,11 \%$ with $501-1000$ employees, and $11 \%$ with more than 1,000 employees.

Of the 122 healthcare employees, $62 \%$ were female and $89 \%$ were employed full-time. The mean age of employees was 45 years $(S D=11)$. Of the participants who reported their organizational tenure, the average tenure was 11 years $(\mathrm{SD}=9)$. The sample included similar job types as in Study 1, such as physiotherapists, doctors, assistants, nurses, midwives, patient advisors, general practitioners, dental practitioners and medical interns.

\section{Measures}

We followed the same back-translation procedure (Brislin et al., 1973) used in Study 1 and administered the survey in Turkish. We used the same measures used in Study 1 to assess satisfaction with job resources, anxiety, depression, and behavioral stress indicators. To operationalize mistreatment by patients, we utilized a customer interpersonal injustice scale. Unless otherwise noted, employees responded to a 5-point Likert-type scale (1 = strongly disagree and 5 = strongly agree) .

Mistreatment by patients. We operationalized mistreatment by patients using an eight item interpersonal injustice scale developed by Skarlicki, van Jaarsveld, and Walker (2008). We adapted the items by replacing the "customer" with "patient or patient relative”. Response options ranged from "never" to "always". A sample item was "A patient or patient relative who doubted your ability” $(\alpha=.91)$.

Control variables. In Study 2, due to space considerations, we controlled for overall tension experienced by the employee as opposed to Type A personality, given the length of the Type A personality questionnaire. We used the seven-item Job Induced Tension scale by House 
and Rizzo (1972) in order to measure employees’ job induced tension levels. We asked the participants to indicate to what extent they agreed with each item. A sample item was "I work under a great deal of tension” ( $\alpha=.89$ ). Following Study 1, we controlled for sex. Finally, following past research (Kipnis and Schmidt, 1988), we also controlled for the number of employees as an indicator of organizational size.

\section{Results}

Means, standard deviations, and correlations are presented in Table 4. We tested all hypotheses using hierarchical moderated regression procedures in SPSS 23, and the results are presented in Tables 5 and 6. A hierarchical regression model was conducted separately for each outcome variable (anxiety, depression, and behavioral stress indicators), controlling for job induced tension, sex, and number of employees. We followed the same procedure we utilized in Study 1.

Insert Table 4 about here

The results for Hypotheses 1a and $1 \mathrm{~b}$ are presented in Table 5 and Table 6. The interaction term of mistreatment by patients and satisfaction with job resources was not significant with respect to anxiety or depression, failing to support Hypotheses 1a or 1b. In the one-organization sample, this interaction was significant for depression. Therefore, in this sample, this finding was not replicated.

Insert Table 5 and Table 6 about here 


\section{BITING THE HAND THAT HEALS}

The interaction terms of mistreatment by patients and satisfaction with job resources were significant with respect to behavioral stress indicators $\left(\beta=.19, p<.05, \Delta \mathrm{R}^{2}=.03\right)$, providing support for Hypotheses 2. The plot of the significant interaction between mistreatment by patients and satisfaction with job resources is presented in Figure 4. The results suggest that for employees with high satisfaction with job resources, there was a positive relationship between mistreatment by patients and behavioral stress indicators $(\beta=.34, t=2.80, p<.01)$. However, for employees with low satisfaction with job resources, there was no support for a relationship between mistreatment by patients and behavioral stress indicators $(\beta=-.11, t=-.10, p>.05)$. These findings are in line with Hypothesis 2, replicating the findings in the multi-organizations sample with the use of a different mistreatment by patients scale.

In order to see which behavioral stress indicators were predicted by the interaction term, we performed a series of logistic regression analysis. The interaction term was found to be a significant predictor only for the analgesics consumption $(\mathrm{B}=1.13, \mathrm{SE}=.37$, Wald $=9.29, p<$ .01 ), and psychopharmaceutical consumption ( $\mathrm{B}=.75, \mathrm{SE}=.38$, Wald $=3.86, p<.05)$.

\section{Discussion}

This study attempted to expand the existing literature on outsider mistreatment by examining the potential buffering effect of satisfaction with job resources on employees' well-being. Previous research examining outsider mistreatment tended to focus on how mistreatment from customers affected organizational and job attitudes or employee retaliation against customers. The aim in our study was to examine how mistreatment from outsiders affects employees themselves. Our study was designed particularly to understand if job resources protected healthcare providers from the negative effects of stress due to patient mistreatment on mental and physical health outcomes. Based on the JD-R model, we suggested that patient mistreatment would interact with 


\section{BITING THE HAND THAT HEALS}

satisfaction with job resources to predict anxiety, depression, and behavioral stress indicators in healthcare workers. Thus, we proposed that employees with higher levels of satisfaction with job resources would be less negatively affected by mistreatment with respect to anxiety, depression, and behavioral stress indicators.

Results of Study 1 were supportive of an interaction between mistreatment by patients and job resources only for depression and behavioral stress indicators and in a surprising direction. In Study 1, satisfaction with job resources moderated the relation of stress due to patient mistreatment to depression and behavioral stress indicators. These results support our argument that stress due to patient treatment will have health implications for employees. At the same time, the nature of the relationship was different from our expectation. Contradicting our prediction, results showed that employees with higher levels of satisfaction with job resources were more negatively affected by patient mistreatment when depression and behavioral stress indicators were considered as outcome variables. It seems that when employees perceive their job-related conditions as favorable (high satisfaction with job resources condition) they may become even more sensitive to how they are treated by patients. Only in the high satisfaction with job resources condition, depression level and behavioral stress indicators were positively related to patient related stress, suggesting that those employees who have high access to resources may be increasing their expectations of how they should be treated by those around them and by those who they serve. In other words, higher satisfaction with job resources might be creating feelings of entitlement and expectations regarding fair treatment and increasing the demand for justice or reducing the tolerance for disrespectful treatment.

In Study 2, we examined satisfaction with job resources as moderators of the relationship between patient interpersonal injustice and health outcomes of healthcare employees in Turkey. 


\section{BITING THE HAND THAT HEALS}

In this sample we used a justice scale and drew from a more diverse sample representing a greater number of organizations. Results suggested that patient interpersonal injustice was positively related to behavioral stress indicators only when satisfaction with job resources was high. This finding partially replicates results from the Study 1 where we collected data only from one organization, a leading training and research university hospital in Istanbul. These results indicate further support for the sensitizing role of satisfaction with job resources for patient interpersonal injustice. The results using this scale were significant only for behavioral stress indicators, suggesting that the stress due to patient scale may capture critical aspects of the mistreatment faced by healthcare workers more effectively than the injustice scale.

\section{Theoretical Implications}

Our first goal in this research was to extend the existing knowledge on outsider injustice outcomes by examining mental health and behavioral stress indicators as potential outcomes of mistreatment by patients. While doing this, our main focus was on testing the role of job related resources on this relationship. We found that satisfaction with job resources was indeed a moderator in the relation of mistreatment by patients with depression and unhealthy behaviors. In particular, results showed that the more employees experienced stress due to mistreatment by patients the more they were depressed and showed higher levels of behavioral stress indicators, but only if they had higher levels of satisfaction with job resources. This finding is interesting due to pointing out that having more job resources may not be sufficient for these employees to cope with this particular demand of their jobs.

Secondly, basing our predictions on the JD-R model, we suggested that satisfaction with job resources would have a buffering role on the impact of mistreatment by patients on health outcomes. The impact of satisfaction with job resources on this relation appeared to be 


\section{BITING THE HAND THAT HEALS}

sensitizing rather than buffering. It seems employees with higher satisfaction with job resources become even more sensitive to poor treatment. This result shows that JD-R model does not provide an adequate explanation in this research setting. Employees whose satisfaction levels are higher for job resources may have higher expectations about how they should be treated. Relative deprivation theory (Crosby, 1976; Folger, 1986) suggests that it is not the objective status of the individual, but the feeling that one is not receiving the treatment one is entitled to have results in dissatisfaction. It is plausible that employee reactions to patient mistreatment can be explained by a relative deprivation explanation: Instead of enabling employees to better cope with their job demands, the availability of resources to employees may create the sense that the organization supports and cares for them, which is in direct contrast to how these workers are treated by their patients. This dissonance may be resulting in more harmful health consequences. In order to gain more insight into the unexpected findings, we conducted follow-up interviews with three healthcare workers. We described the study findings to them to gain their insights. The interviewees noted two possible explanations. The first one was aligned with our relative deprivation-based rationale: Employees who are treated better by their organizations (those who have access to greater resources) may be more sensitive to mistreatment by patients because they have greater expectations regarding how they should be treated. Further, the interviewees offered a second plausible explanation: Employees who do not have access to high levels of resources display greater empathy to patients who mistreat them, because they may attribute these behaviors to systemic factors. In other words, they may believe that the system fails both workers and patients, and therefore they may not be personally affronted by the mistreatment they receive. These potential explanations suggest that resources seem to play a role that is different from what would have been predicted by the JD-R model. 


\section{BITING THE HAND THAT HEALS}

Third, our findings make a contribution by examining the concept of patient mistreatment in a context where it is an important concern. It is interesting that patient mistreatment does not have any main effects on anxiety, depression, or behavioral indicators. Instead, patient mistreatment has a negative influence over a person's health and well-being only some of the time. Rather than helping employees cope with this stressor better, having access to greater job resources in the form of recognition received for good work, opportunity to use one's ability, amount of variety in job, amount of responsibility given, and freedom to choose one's own method of working are sensitizing factors for these employees. It is important to investigate why this is the case. It is plausible that access to resources increases expectations about how the employee should be treated. Alternatively, employees may experience greater levels of hopelessness when they experience injustice even though they are structurally in a privileged situation. If patient injustice is a reality despite the presence of autonomy, financial resources, and coworker support, individuals may be feeling that this situation is unlikely to be resolved in the future, increasing the harmful effects of experienced injustice.

\section{Practical Implications}

In addition to the theoretical contributions mentioned above, this research yields certain practical implications. First, by focusing on the boundary conditions for customer injustice, we highlight a distinction between how job resources and treatment from patients interact in the prediction of well-being indicators of healthcare employees. The analysis of main effects provide an insight into the extent to which outsiders influence the psychological and physiological wellbeing of employees. Having found no main effects while finding support for interactional effects, our results point out that organizations have a central role in dealing with mistreatment issues even stemming from outsiders. 


\section{BITING THE HAND THAT HEALS}

More importantly, mistreatment by patients was found to have more harmful implications for the ones who actually have high satisfaction with job resources. Our predictions were based on the idea that job resources would provide a coping mechanism for employees with higher resource satisfaction. On the contrary, results showed that higher satisfaction with resources resulted in higher sensitivity about fair treatment. This finding suggests that simply providing a strong work environment in terms of job resources may not strengthen employee resilience against unfair treatment by customers or patients. Instead, organizations may need to investigate how to prevent customer injustice to begin with, or how to increase employee resilience.

Preventive actions may include implementing monitoring systems and staffing trained guards to keep the caregiving environment secure. Designing relatively less isolated work settings, and providing effective supervision (Sundram, 1984) of direct care staff may play a deterrent role for patients with mistreatment tendencies. Designing offices and waiting rooms to prevent patients and relatives from waiting in large groups may also help to create a less threatening environment. For increasing employee resilience, some other approaches might be directly teaching them how to handle these occurrences, increasing emotional control and social support of coworkers, and creating a culture of mutual respect (Kaplan et al., 2010). For this purpose, healthcare education institutions may consider developing a curriculum for healthcare education including courses on how to treat patients, how to manage emotions, and how to professionally handle the unfair or aggressive behaviors within the healthcare organization setting. For those who are already in the workforce, training programs (Albina, 2016) and simulation experiences could be designed to increase awareness and to provide capability of balancing emotional reactions and to cope with certain foreseeable conditions. 


\section{BITING THE HAND THAT HEALS}

\section{Potential Limitations and Future Research Directions}

One potential limitation of this research was the methodology used. The empirical tests of the hypotheses were based on same source survey data from a field study. Same source bias is unlikely to result in spurious interaction effects (Siemsen et al., 2010). At the same time, collecting health outcomes from a secondary source such as a friend or significant other of the employee would have increased the reliability of the responses.

A second potential limitation relates to how we operationalized employee health outcomes. It would have been ideal to actually measure health outcomes using health metrics such as blood pressure, pulse rate, sedimentation, etc. for better precision and higher validity. Self-reports of anxiety and depression are relevant and important outcomes (Lonigan et al., 1994), but supplementing these outcomes with objective metrics would have increased our understanding of how patient injustice affects employee health and well-being.

Because our data collection approach was cross-sectional, the directionality of results is uncertain. For example, employees may be more likely to be harassed by patients if they are anxious or depressed to begin with. While this study treats mistreatment as a predictor, longitudinal data would provide more evidence regarding the direction of causality. Additionally this would allow us to investigate short term and long term consequences of patient injustice. With regard to actual intervention strategies that would prevent the negative effects of patient injustice on healthcare employees, we really need longitudinal studies to see whether increases in job resources may aid supporting employees. If, in fact, research supports the interaction effects found in this study, organizations offering higher job resources will probably not obtain better results in terms of minimizing unhealthy outcomes for employees treated poorly by patients. Future research would benefit from examining these possibilities. 


\section{BITING THE HAND THAT HEALS}

The sampling methodology introduces some limitations as well. Even though the sample for Study 1 included a variety of job types and reflected patient-interfacing employees, it was limited to a single organization. Because organizational factors may also have played a role in the emergence of our unexpected findings, replicating the results using data from multiple organizations would increase confidence in our results. We executed Study 2 to complement Study 1, reaching out to group of employees representing a wider spectrum of organizations, snowball sampling limits the generalizability of the results. Study 2 captures organizations that were large and well established, but also organizations and smaller clinics that were not represented in our Study 1 sample. Thus, Study 1 and Study 2 have their own limitations and results must be interpreted accordingly.

With respect to demographic characteristics the sample was predominately females (53\% in Study 1 and 62\% in Study 2) and with respect to employment characteristics full-time employees dominated the samples (89\% in Study 1 and 89\% in Study 2). One important way in which our results could have been influenced by the sample composition was the failure to capture any different patterns of interactions that might stem from vulnerability or resource differences between these sub groups. Even though we controlled for sex in our analysis to ensure that the pattern of interactions could not be attributable to differential associations with this variable, these factors could affect the generalizability of our results. Including or excluding the type of employment variable in our analysis did not lead to any changes in the results reported. In addition, the overall sample size in Study 2 was small $(n=122)$. Although Hypothesis 2 showed the same pattern in both studies, a larger sample might provide more consistency between Study 1 and Study 2. 


\section{BITING THE HAND THAT HEALS}

This study investigates the influence of patient injustice with a relatively isolated approach, focusing only on the employees’ perception. Future studies would benefit from an interactionist approach to clearly examine the action-reaction nature of the patient injustice. Considering the two-way interaction between patients and healthcare providers, it may not be appropriate to treat patient injustice simply as an antecedent even when studying initial experiences of healthcare employees with their patients. Unfair treatment might be an outcome driven by acts, communication style, and/or body language of the healthcare employees. Furthermore, this mutual interaction possesses unique exchange characteristics which differentiates it from a typical customer-service provider relationship, such as the satisfaction derived from helping others. Thus, a key issue that warrants further investigation is the influence of reciprocity in the relationship of patients and healthcare providers.

Researchers in future studies could also consider the unequal nature of variables of interest. For example, certain outsider behaviors may be ignored by employees while others having a bigger impact on outcomes. Furthermore well-being indicators are not homogenous with regards to their destructive effects on employees and abiding impact to stimulate further mistreatment. While the focus of this study was on the boundary conditions that result in negative well-being indicators, more research is clearly needed to examine different behavioral outcomes in more depth, differentiating between their predictors. Our results suggested that slightly different behavioral outcomes predicted by our model, with analgesic consumption predicted by the interaction term in both studies, but Study 1 also including smoking and irregular eating, while Study 2 including psychopharmaceutical consumption. It is important to examine when and why different behavioral indicators may be affected by patient mistreatment. 


\section{BITING THE HAND THAT HEALS}

Finally, future attempts to replicate this research should be conducted in a variety of settings and among different occupational groups. We studied one industry and one country where a dramatic change process has been implemented in the healthcare system since 2003 (Atilgan et al., 2017). With the recent regulations, public health insurance schemes are unified, number of citizens covered for care is increased, health care coverage network is extended to include private hospitals, performance based employee payment schemes are enacted, and information systems and investments on infrastructure are upgraded (Erus and Hatipoglu, 2017). These changes resulted in a heavy work load for health care workers, with high levels of government regulation regarding number of patients each doctor has to take care of in a short amount of time. In other words, systemic factors resulting adversarial relations between health care workers and patients certainly exist. It is important to examine whether the results generalize to other populations. Future research would benefit from examining whether the results generalize to customer injustice (e.g., retail workers) so that a more informed understanding of the role of outsiders on the interaction of justice perceptions and well-being outcomes can be developed.

\section{Conclusion}

The results of this study suggest that satisfaction with job resources is a relevant variable that has a moderating effect on how mistreatment by patients results in depression and unhealthy habits. Given the positive relationship of mistreatment by patients with depression and unhealthy habits for highly satisfied employees with job resources, and non-significant relationship of the same variables for less satisfied employees, our findings revealed that mistreatment by patients resulted in depression and unhealthy habits only for highly satisfied employees. That is, satisfaction with job resources play a sensitizing role, rather than a buffering one, opposite to our 


\section{BITING THE HAND THAT HEALS}

expectations. Highly satisfied employees with job resources seem to be subjects of more destructive results when exposed to unfair treatment. It seems to be important and fruitful to examine the unique factors contributing to this unexpected pattern of relationship and the individuating impact of satisfaction with job resources. 


\section{BITING THE HAND THAT HEALS}

\section{References}

Aiken, L. S., West, S. G. and Reno, R. R. (1991), Multiple Regression: Testing and Interpreting Interactions, Sage, Thousand Oaks, CA.

Albina, J.K. (2016), "Patient abuse in the health care setting: The nurse as patient advocate”, AORN Journal, Vol. 103, Iss. 1, pp. 73-81.

Arnold, K. A. and Walsh, M. M. (2015), “Customer incivility and employee well-being: Testing the moderating effects of meaning, perspective taking and transformational leadership”, Work \& Stress, Vol. 29, pp. 362-378.

Atilgan, E., Kilic, D. and Ertugrul, H. M. (2017), “The dynamic relationship between health expenditure and economic growth: Is the health-led growth hypothesis valid for Turkey?.”, The European Journal of Health Economics, Vol. 18, pp. 567-574.

Bakker, A. B. and Demerouti, E. (2007), “The job demands-resources model: State of the art”, Journal of Managerial Psychology, Vol. 22, pp. 309-328.

Bakker, A. B., Demerouti, E., Taris, T. W., Schaufeli, W. B. and Schreurs, P. J. (2003), “A multigroup analysis of the job demands-resources model in four home care organizations”, International Journal of Stress Management, Vol. 10, pp. 16-38.

Bakker, A. B., Demerouti, E. and Verbeke, W. (2004), “Using the job demands-resources model to predict burnout and performance”, Human Resource Management, Vol. 43, pp. 83104.

Batıgün, A. D. and Şahin, N. H. (2006), “İşs stresi ve sağlık psikolojisi araştırmaları için iki ölçek: A-tipi kişilik ve iş doyumu”, Türk Psikiyatri Dergisi, Vol. 17, pp. 32-45.

Berry, L. L. and Seiders, K. (2008), “Serving unfair customers”, Business Horizons, Vol. 51, pp. 29-37. 


\section{BITING THE HAND THAT HEALS}

Bies, R. J. and Moag, J. S. (1986), “Interactional justice: Communication criteria of fairness”, Research on Negotiation in Organizations, Vol. 1, pp. 43-55.

Bitner, M. J., Booms, B. H. and Mohr, L. A. (1994), “Critical service encounters: The employee's viewpoint”, The Journal of Marketing, Vol. 58, pp. 95-106.

Bolger, N. and Zuckerman, A. (1995), “A framework for studying personality in the stress process”, Journal of Personality and Social Psychology, Vol. 69, pp. 890-902.

Brislin, R. W., Lonner, W. J. and Thorndike, R. M. (1973), Cross-cultural Research Methods, J. Wiley, New York, NY, pp. 32-58.

Bucik, V. and Brenk, K. (1997), “Internal and external validation of the Bortner Type A behaviour scale”, Review of Psychology, Vol. 4, pp. 25-39.

Campana, K. L. and Hammoud, S. (2015), “Incivility from patients and their families: Can organisational justice protect nurses from burnout?”, Journal of Nursing Management, Vol. 23, pp. 716-725.

Caplan, R. D. (1971), “Organizational stress and individual strain: A social-psychological study of risk factors in coronary heart disease among administrators, engineers, and scientists”, available at: http://ntrs.nasa.gov/archive/nasa/casi.ntrs.nasa.gov/19720005404.pdf (accessed 12 November 2015).

Caplan, R. D., Cobb, S. and French, J. R. (1975), “Relationships of cessation of smoking with job stress, personality, and social support”, Journal of Applied Psychology, Vol. 60, pp. 211-219.

Carver, C. S. (1980), "Perceived coercion, resistance to persuasion, and the Type A behavior pattern”, Journal of Research in Personality, Vol. 14, pp. 467-481. 


\section{BITING THE HAND THAT HEALS}

Ciccone, A. (2011), “Unhealthy employees cost businesses $\$ 153$ billion in lost productivity”, available at: http://www.huffingtonpost.com/2011/10/17/unhealthy-employees-cost-153billion_n_1016568.html (accessed 25 February 2016).

Colquitt, J. A., Conlon, D. E., Wesson, M. J., Porter, C. O. and Ng, K. Y. (2001), “Justice at the millennium: A meta-analytic review of 25 years of organizational justice research”, Journal of Applied Psychology, Vol. 86, pp. 425-445.

Cooper, C. L., Rout, U. and Faragher, B. (1989), "Mental health, job satisfaction, and job stress among general practitioners”, BMJ, Vol. 298, pp. 366-370.

Cropanzano, R., Goldman, B. M. and Benson III, L. (2005), “Organizational justice”, in Barling, J., Kelloway E. K. and Frone, M. R. (Eds.), Handbook of Work Stress, Sage, Thousand Oaks, CA, pp. 63-87.

Cropanzano, R., Prehar, C. A. and Chen, P. Y. (2002), "Using social exchange theory to distinguish procedural from interactional justice”, Group \& Organization Management, Vol. 27, pp. 324-351.

Crosby, F. (1976), “A model of egoistical relative deprivation”, Psychological Review, Vol. 83, pp. 85-113.

Crown, S and Crisp, A. H. (1966), “A short clinical diagnostic self-rating scale for psychoneurotic patients”, British Journal of Psychiatry, Vol. 112, pp. 917-923.

De Lange, A. H., Taris, T. W., Kompier, M. A., Houtman, I. L. and Bongers, P. M. (2005), "Different mechanisms to explain the reversed effects of mental health on work characteristics”, Scandinavian Journal of Work, Environment \& Health, Vol. 31, pp. 314. 


\section{BITING THE HAND THAT HEALS}

Deccan Herald (2016), “Attacked by patient’s kin, doctors strike work”, available at:

http://www.deccanherald.com/content/559489/attacked-patients-kin-doctors-strike.html (accessed 28 January 2017).

Demerouti, E., Bakker, A. B., Nachreiner, F. and Schaufeli, W. B. (2001), “The job demandsresources model of burnout”, Journal of Applied Psychology, Vol. 86, pp. 499-512.

Dormann, C. and Zapf, D. (2004), “Customer-related social stressors and burnout”, Journal of Occupational Health Psychology, Vol. 9, pp. 61-82.

Erus, B. and Hatipoglu, O. (2017), "Physician payment schemes and physician productivity: Analysis of Turkish healthcare reforms”, Health Policy, Vol. 121, pp. 553-557.

Findorff, M. J., McGovern, P. M., Wall, M., Gerberich, S. G. and Alexander, B. (2004), “Risk factors for work related violence in a health care organization”, Injury Prevention, Vol. 10, pp. 296-302.

Folger, R. (1986), “A referent cognitions theory of relative deprivation”, in Olson, J. M., Herman, C. P. and Zanna, M. P. (Eds.), Relative Deprivation and Social Comparison: The Ontario Symposium Vol. 4, Psychology Press of Taylor \& Francis Group, Erlbaum Hillsdale, NJ, pp. 33-55.

Folger, R. and Konovsky, M. A. (1989), “Effects of procedural and distributive justice on reactions to pay raise decisions”, Academy of Management Journal, Vol. 32, pp. 115-130.

Gates, D. M., Ross, C. S. and McQueen, L. (2006), “Violence against emergency department workers”, The Journal of Emergency Medicine, Vol. 31, pp. 331-337.

Grandey, A. A., Dickter, D. N. and Sin, H. P. (2004), “The customer is not always right: Customer aggression and emotion regulation of service employees”, Journal of Organizational Behavior, Vol. 25, pp. 397-418. 


\section{BITING THE HAND THAT HEALS}

Granner, M. L., Black, D. R. and Abood, D. A. (2002), “Levels of cigarette and alcohol use related to eating-disorder attitudes”, American Journal of Health Behavior, Vol. 26, pp. 43-55.

Ho, V. T. and Gupta, N. (2014), "Retaliating against customer interpersonal injustice in a Singaporean context: Moderating roles of self-efficacy and social support”, Applied Psychology: An International Review, Vol. 63, pp. 383-410.

House, R. J., \& Rizzo, J. R. (1972). “Toward the measurement of organizational practices: Scale development and validation”, Journal of Applied Psychology, Vol. 56, 388-396.

Kaplan, K., Mestel, P., and Feldman, D. L. (2010), “Creating a culture of mutual respect”, AORN Journal, Vol. 91, 495-510.

Kasl, S. V., Gore, S. and Cobb, S. (1975), “The experience of losing a job: Reported changes in health, symptoms and illness behavior”, Psychosomatic Medicine, Vol. 37, pp. 106-122.

Kipnis, D., \& Schmidt, S. M. (1988). “Upward-influence styles: Relationship with performance evaluations, salary, and stress”, Administrative Science Quarterly, Vol. 33, pp. 528-542.

Kirmeyer, S. L. (1988), “Coping with competing demands: Interruption and the Type A pattern”, Journal of Applied Psychology, Vol. 73, pp. 621-629.

Kisa, S. (2008), “Turkish nurses’ experiences of verbal abuse at work”, Archives of Psychiatric Nursing, Vol. 22, pp. 200-207.

Lavelle, J. J., Rupp, D. E., \& Brockner, J. (2007), “Taking a multifoci approach to the study of justice, social exchange, and citizenship behavior: The target similarity model”, Journal of Management, Vol. 33, pp. 841-866.

LeBlanc, M. M. and Kelloway, E. K. (2002), “Predictors and outcomes of workplace violence and aggression”, Journal of Applied Psychology, Vol. 87, pp. 444-453. 
Liu., X. C., Keyes K. M. and Li, G. (2014), “Work stress and alcohol consumption among adolescents: Moderation by family and peer influences”, BMC Public Health, Vol. 14, pp. 1172-1185.

Lonigan, C. J., Carey, M. P. and Finch, A. J. (1994), “Anxiety and depression in children and adolescents: Negative affectivity and the utility of self-reports”, Journal of Consulting and Clinical Psychology, Vol. 62, pp. 1000-1008.

Maslach, C. and Jackson, S. E. (1984), "Burnout in organizational settings”, Applied Social Psychology Annual, Vol. 5, pp. 133-153.

Moschis, G. P. and Cox, D. (1989), “Deviant consumer behavior”, Advances in Consumer Research, Vol. 16, pp. 732-737.

Newton, T. J., \& Keenan, A. (1990), “The moderating effect of the Type A behavior pattern and locus of control upon the relationship between change in job demands and change in psychological strain”, Human Relations, Vol. 43, pp. 1229-1255.

Parks, G. A. and Anderson, B. K. (2004), “Cognitive-behavioral alcohol treatment”, in Heather, N. and Stockwell, T. (Eds.), The Essential Handbook of Treatment and Prevention of Alcohol Problems, John Wiley \& Sons, West Sussex, pp. 69-86.

Pritchard, M. E., Wilson, G. S. and Yamnitz, B. (2007), "What predicts adjustment among college students? A longitudinal panel study", Journal of American College Health, Vol. 56, pp. 15-22.

Rathus, S. A. and Nevid, J. S. (1989), Psychology and the Challenges of Life: Adjustment and Growth, Holt Rinehart, \& Winston, Fort Worth, TX. 
Rupp, D. E., \& Cropanzano, R. (2002), “The mediating effects of social exchange relationships in predicting workplace outcomes from multifoci organizational justice”, Organizational Behavior and Human Decision Processes, Vol. 89, pp. 925-946.

Rupp, D. E. and Spencer, S. (2006), "When customers lash out: The effects of customer interactional injustice on emotional labor and the mediating role of discrete emotions", Journal of Applied Psychology, Vol. 91, pp. 971-972.

Saules, K. K., Pomerleau, C. S., Snedecor, S. M., Mehringer, A. M., Shadle, M. B., Kurth, C. and Krahn, D. D. (2004), "Relationship of onset of cigarette smoking during college to alcohol use, dieting concerns, and depressed mood: Results from the Young Women's Health Survey”, Addictive Behaviors, Vol. 29, pp. 893-899.

Shao, R. and Skarlicki, D. P. (2014), “Service employees’ reactions to mistreatment by customers: A comparison between North America and East Asia”, Personnel Psychology, Vol. 67, pp. 23-59.

Siemsen, E., Roth, A. and Oliveira, P. (2010), “Common method bias in regression models with linear, quadratic, and interaction effects”, Organizational Research Methods, Vol. 13, pp. 456-476.

Skarlicki, D. P., van Jaarsveld, D. D. and Walker, D. D. (2008), “Getting even for customer mistreatment: The role of moral identity in the relationship between customer interpersonal injustice and employee sabotage”, Journal of Applied Psychology, Vol. 93, pp. 1335-1347.

Sliter, M. T. and Boyd, E. M., (2015), “But we're here to help! Positive buffers of the relationship between outsider incivility and employee outcomes”, European Journal of Work and Organizational Psychology, Vol. 24, pp. 225-238. 
Sowislo, J. F. and Orth, U. (2013), “Does low self-esteem predict depression and anxiety? A meta-analysis of longitudinal studies”, Psychological Bulletin, Vol. 139, pp. 213-240.

Spector, P. E., \& O'Connell, B. J. (1994), “The contribution of personality traits, negative affectivity, locus of control and Type A to the subsequent reports of job stressors and job strains”, Journal of Occupational and Organizational Psychology, Vol. 67, pp. 1-12.

Speroni, K. G., Fitch, T., Dawson, E., Dugan, L. and Atherton, M. (2014), “Incidence and cost of nurse workplace violence perpetrated by hospital patients or patient visitors”, Journal of Emergency Nursing, Vol. 40, pp. 218-228.

Sullivan, C. and Yuan, C. (1995), "Workplace assaults on minority health and mental health care workers in Los Angeles”, American Journal of Public Health, Vol. 85, pp. 1011-1014.

Sundram, C.J. (1984). “Obstacles to reducing patient abuse in public institutions”, Hospital and Community Psychiatry, Vol. 35, pp. 238-243.

Torres, S. J. and Nowson, C. A. (2007), "Relationship between stress, eating behavior, and obesity”, Nutrition, Vol. 23, pp. 887-894.

Vredenburgh, L. D., Carlozzi, A. F. and Stein, L. B. (1999), "Burnout in counseling psychologists: Type of practice setting and pertinent demographics”, Counseling Psychology Quarterly, Vol. 12, pp. 293-302.

Warr, P., Cook, J. and Wall, T. (1979), "Scales for the measurement of some work attitudes and aspects of psychological well-being”, Journal of Occupational Psychology, Vol. 52, pp. 129-148.

Xanthopoulou, D., Bakker, A. B., Dollard, M. F., Demerouti, E., Schaufeli, W. B., Taris, T. W. and Schreurs, P. J. (2007), “When do job demands particularly predict burnout? The 
moderating role of job resources”, Journal of Managerial Psychology, Vol. 22, pp. 766786.

Yang, J. and Diefendorff, J. M. (2009), “The relations of daily counterproductive workplace behavior with emotions, situational antecedents, and personality moderators: A diary study in Hong Kong”, Personnel Psychology, Vol. 62, pp. 259-295. 


\section{Table Captions}

Table 1. Study 1 means, standard deviations, and intercorrelations among variables.

Table 2. Study 1 results of moderated hierarchical regression analyses with anxiety and depression as dependent variables.

Table 3. Study 1 results of moderated hierarchical regression analyses with behavioral stress indicators as dependent variable.

Table 4. Study 2 means, standard deviations, and intercorrelations among variables.

Table 5. Study 2 results of moderated hierarchical regression analyses with anxiety and depression as dependent variables.

Table 6. Study 2 results of moderated hierarchical regression analyses with behavioral stress indicators as dependent variable. 


\section{Figure Captions}

Figure 1. Study model.

Figure 2. Satisfaction with resources as a moderator of stress due to patient injustice - depression relationship (Study 1).

Figure 3. Satisfaction with resources as a moderator of stress due to patient injustice - behavioral stress indicators relationship (Study 1).

Figure 4. Satisfaction with resources as a moderator of patient interpersonal injustice behavioral stress indicators relationship (Study 2). 


\section{Appendix}

Mistreatment by Patients (Study 1)

1. Fear of assault during night visits

2. Increased demand by patients and relatives for second opinion from hospital specialists

3. No appreciation of your work by patients

4. Worrying about patients' complaints

5. Adverse publicity by media

6. Unrealistically high expectations of your role

Mistreatment by Patients (Study 2)

1. Refused to listen to you

2. Interrupted you: Cut you off mid sentence

3. Made demands that you could not deliver

4. Raised irrelevant discussion

5. Doubted your ability

6. Yelled at you

7. Used condescending language (e.g., "you are an idiot”)

8. Spoke aggressively to you

Satisfaction with job resources (Study 1 \& 2)

1. Amount of responsibility you are given

2. Freedom to choose your own method of working

3. Amount of variety in your job

4. Your fellow workers

5. Physical working conditions

6. Opportunity to use your ability

7. Your rate of pay

8. Recognition you get for your good work

9. Your hours of work

10. Overall job satisfaction

Anxiety ((Study 1 \& 2)

1. Upset for no reason

2. Might faint

3. Uneasy and restless

4. Panicky

5. Worrying 
6. Strung up inside

7. Going to pieces

8. Bad dreams

\section{Depression ((Study 1 \& 2)}

1. Think slower than usual

2. Life is too much effort

3. Regret past behavior

4. Wake up unusually early

5. Sadness

6. Extra effort to face crises

7. Need to cry

8. No sympathy for others

Behavioral Stress Indicators ((Study 1 \& 2)

1. Cigarette consumption

2. Alcohol consumption

3. Analgesics consumption

4. Psychopharmaceutical consumption

5. Irregular eating habits

\section{Type A Personality ((Study 1)}

1. Stressing certain words while talking

2. Eating and walking fast

3. Believing that children should be encouraged to compete

4. Feeling uncomfortable when observed a person working in a slow pace

5. Speeding up people while they are talking

6. Feeling angry when stuck in traffic or waiting in a que to get into a restaurant

7. Dealing with your own problems even when you are waiting for somebody

8. Trying to multitask (E.g. shaving or hair drying while eating, etc.)

9. Trying to complete work at holidays

10. Drawing conversations towards your points of interest

11. Feeling guilty when spent time just for relaxing

12. Pitching in your job so much not even realizing the decoration of the workplace or the view outside the window

13. Feeling obliged to accomplish more instead of putting time on creativity or social issues

14. Planning for doing even more in even less time

15. Always being on time for appointments

16. Clenching fingers in the palm or fisting on the desk while talking in order to emphasize your views 
17. Attributing your success to your capability of working fast

18. Feeling that duties should be completed immediately and quickly

19. Continuously trying to look for more effective ways to complete tasks

20. Insisting on winning rather than enjoying games

21. Frequently intervening while others are working

22. Feeling uncomfortable when others are late

23. Immediately leaving the table to start working after meals

24. Being in a hurry (feeling that you have to immediately complete things)

25. Being unsatisfied with your current efficiency level

\section{Job Induced Tension (Study 2)}

1. My job tends to directly affect my health

2. I work under a great deal of tension

3. I have felt fidgety or nervous as a result of my job

4. If I had a different job, my health would probably improve

5. Problems associated with my job have kept me awake at night

6. I have felt nervous before attending meeting in the company

7. I often "take my job home with me" in the sense that I think about it when doing other things 